\title{
Imitar al que imita: \\ Castillo Solórzano y el Epítome a la historia de fray Tomás de Villanueva de Quevedo ${ }^{1}$
}

\author{
Cristina Castillo Martínez \\ Universidad de Jaén \\ Facultad de Humanidades y Ciencias de la Educación \\ Departamento de Filología Española \\ Edificio D2, 026 \\ Las Lagunillas s/n \\ 23071 Jaén \\ ccastill@ujaen.es
}

[La Perinola, (Issn: 1138-6363), 22, 2018, pp. 413-426]

DOI: $10.15581 / 017.22 .413-426$

\section{Introducción: el Sagrario de Valencia de Castillo Solórzano}

Entre la amplísima producción literaria de Alonso de Castillo Solórzano, destaca por la singularidad de su contenido un volumen hoy poco conocido que lleva por título Sagrario de Valencia (Valencia, Silvestre Esparsa, 1635). Se trata de un compendio de siete historias de santos -o beatos por entonces- nacidos en Valencia o vinculados con esta ciudad: san Vicente mártir, san Vicente Ferrer, fray Tomás de Villanueva, fray Luis Bertrán, san Bernardo de Alcira, fray Pascual Bailón y san Francisco de Borja, por este orden. A ellos se les suma un último apartado (sin epígrafe), centrado en la «relación de las imágenes y reliquias de devoción que hay en Valencia», como se dice en el sumario.

La obra nacía con la idea, según afirma el propio Castillo Solórzano en la dedicatoria a la ciudad, «de que saliesen a la luz juntas las vidas de tan provectos varones que se ven en diferentes tomos separadas», y con el objetivo, al menos en un primer término, de que sirviera para "gloria y honra de Dios, Nuestro Señor, y de su Santísima Madre y de sus santos, para que los tenga juntos en un cuerpo y volumen y no anden separados en diferentes libros»»2.

Un texto basado en tales premisas y con semejante temática desentonaba de la producción de un autor conocido por la poesía jocosa de sus Donaires del Parnaso $(1624,1625)$ o por su narrativa picaresca o cor-

1. Este trabajo se inscribe en el marco del Proyecto $\mathrm{I}+\mathrm{D}+\mathrm{i}$ del mineco La novela corta del siglo XVII: estudio y edición (y III) (FFI2017-85417-P).

2. Castillo Solórzano, Sagrario de Valencia, fol. 159r. 
tesana que, si bien daba cabida a piezas teatrales -en una exhibición de hibridismo genérico muy del gusto de la época-, se situaba en las antípodas de lo hagiográfico. Hasta la aparición del Sagrario de Valencia, había publicado más de una decena de títulos con una periodicidad anual, tendencia que mantendría en años siguientes convirtiéndose en uno de los narradores más prolíficos del Barroco. Habían visto la luz Tardes entretenidas (1625), Jornadas alegres (1626), Tiempo de regocijo (1627), Huerta de Valencia (1629), Lisardo enamorado (1629), Noches de placer (1631), Las harpías en Madrid (1631), La niña de los embustes Teresa de Manzanares (1632), Los amantes andaluces (1633) o Fiestas del jardín (1634).

En ese panorama y en un autor que siempre se había mantenido muy cerca de los círculos de poder, extrañaba la escritura de una obra hagiográfica sin que nada significativo (que sepamos) hubiese sucedido en su vida que le llevara a adoptar una línea religiosa, más allá de lo oportuno de cultivar textos que comulgaran con los presupuestos contrarreformistas. Bien es verdad que en algunas obras había incorporado escolios morales -como en Las harpías en Madrid o en los Escarmientos de amor moralizados-, pero como un tipo de ejemplaridad que, en el siglo XVII, se adecuaba sin problema al entretenimiento literario, siguiendo el clásico binomio horaciano del «prodesse et delectare». En el esquema de la hagiografía, sin embargo, no se presuponía más solaz que la edificación a través del relato de las vidas de santos. Con todo, no fue esta su única hagiografía. Justo un año después de la publicación del Sagrario de Valencia, dio a las prensas el Patrón de Alcira, el glorioso mártir san Bernardo (Zaragoza, Pedro Verges, 1636). Hablamos, por tanto, de dos obras de semejantes características, escritas en muy breve lapso de tiempo y ambas vinculadas a la zona levantina, lo que nos hace pensar en alguna motivación fuera de lo religioso que le llevara a hacer ostensible tanto lo hagiográfico como lo valenciano. No hay que olvidar que, aunque Castillo Solórzano nació en Tordesillas, tuvo un estrecho vínculo con la ciudad del Turia, y no solo porque sus padres fueran oriundos de allí, sino también porque él mismo vivió en esta localidad en distintos momentos de su vida y porque en sus imprentas publicó algunas de sus obras (Huerta de Valencia, el Lisardo enamorado y las Fiestas del jardín) ${ }^{3}$.

\section{Las fuentes: Quevedo Silenciado}

Para la confección del Sagrario de Valencia, recurrió a los principales hagiógrafos de cada uno de estos santos o beatos; vía obligada en este ámbito. Así, a la hora de hablar de san Vicente mártir, confiesa seguir a san Isidoro, Prudencio, Simeón, Metafraste y Beda. Cuando le toca el turno a fray Luis Bertrán, se refiere a Baltasar Juan Roca y Gaspar Aguilar. Para tratar de san Bernardo de Alcira, alude a Pedro Antonio Benter, Gaspar Juan Escolano, fray Honorato Gilbau y de Castro o

3. Castillo Martínez, 2017, p. 61. 
Rafael Martí de Viciana, entre otros. Para la vida de san Pascual Bailón recurre a fray Juan Ximénez. Y, para hablar de san Francisco de Borja, su modelo no es otro que Pedro de Ribadeneyra ${ }^{4}$. En todos los casos, Castillo Solórzano sigue a sus modelos dejando constancia de ello en cada apartado. Sin embargo, en algunas ocasiones utiliza fuentes de forma más profusa y sin hacerlo explícito.

Es lo que sucede con el tercer apartado dedicado a fray Tomás de Villanueva, para el que confiesa seguir al agustino valenciano Miguel Bartolomé Salón, uno de sus principales biógrafos, tras Juan de Muñatones:

Sin estos, hizo otros aparecimientos como más largamente cuenta el libro de su vida que escribió el padre Salón, a quien en este breve resumen sigo ${ }^{5}$.

Mayor volumen requería vida tan ejemplar de varón tan consumado en la virtud por quien Dios mostró la grandeza de su poder, pero mi intento es reducir su larga historia a breve resumen. El reverendo padre Salón, cuyo libro he seguido, trata más latamente de todos sus milagros. Remítome a su cuidado, que tuvo más asistencia en él por hacer libro de tantas maravillas ${ }^{6}$.

Si nos atenemos a la literalidad de estas palabras en la primera cita ( (libro de su vida»), estaría siguiendo el Libro de la santa vida y milagros del ilustrísimo y reverendísimo señor Don Fr. Tomás de Villanueva..., que Miguel Bartolomé Salón publicó en Valencia en 1620, después de que tuviera lugar la beatificación y en cuyo proceso ejerció como procurador. No obstante, este agustino, calificador del Santo Oficio y catedrático de Teología en la Universidad de Valencia?, había escrito años antes otra hagiografía de Villanueva como promesa hecha al que llegaría a ser santo por haberlo curado de una enfermedad. El título no incluía el término "vida» por más que lo fuera (Libro de los grandes y singularísimos ejemplos que dejó de sí [...] Don F. Tomás de Villanueva, Valencia, Patricio Mey, 1588), pero no hay que descartar que estuviese en la base de la creación de este apartado del Sagrario de Valencia, en la medida en que aborda su historia.

Se esté refiriendo a una u otra obra, o incluso a ambas, lo importante es que Castillo Solórzano no está diciendo del todo la verdad, pues, aunque conozca los textos de Salón, a quien verdaderamente sigue y, además, de una manera muy fiel, es a Francisco de Quevedo en su Epítome a la historia de la vida de fray Tomás de Villanueva ${ }^{8}$. Es esta una

4. Castillo Martínez, 2017, pp. 65-70.

5. Castillo Solórzano, Sagrario de Valencia, fol. 43r.

6. Castillo Solórzano, Sagrario de Valencia, fols. 43r-v.

7. Más datos acerca de su vida pueden encontrarse en Villegas Rodríguez, 2001.

8. EPITOME / A LA HISTORIA DE LA / vida exemplar, y gloriosa muerte / del bienauenturado F. Thomas de Villanue / ua, Religioso de la Orden de S. Agustin, / y Arçobispo de Valencia. / al Rey nvestro señor. / Autor don Francisco de Queuedo Villegas, / Cauallero del Abito de Santiago. / Año [escudo] 1620 / [filete] / con privilegrio. / En Madrid, Por la viuda de Cosme Delgado / Tassado a 4. marauedis el pliego. $8^{\circ}$ [4] 47 fols. Sig.: ${ }^{2}$, A-F ${ }^{8}$ (Universidad de Toronto, BX Q484 microforma). 
hagiografía que Quevedo escribió por encargo y de manera muy rápida (en unos 12 días) con la intención de que estuviese lista para las fiestas que con motivo de la beatificación organizó la ciudad de Madrid en 1620. En los preliminares se da a entender que es compendio de un texto más extenso en el que estaba trabajando desde hacía diez años. Así lo manifiesta Juan de Herrera - predicador agustino del convento de san Felipe en Madrid y promotor de dicha publicación-, en unas palabras que dirige «A los lectores» ${ }^{9}$. Idea que se alimenta en la aprobación del dominico Jacinto de Colmenares ${ }^{10}$, y en la censura de Francisco Sánchez de Villanueva, capellán y predicador del rey ${ }^{11}$, y que el propio Quevedo se encarga de constatar al final de la obra, tras el «Laus Deo», si es que tales palabras corresponden realmente al autor ${ }^{12}$.

En cualquier caso, ese supuesto proyecto, que pudo fraguarse solo en la mente del escritor, no llegó a publicarse ${ }^{13}$. Lo que nos queda es un texto en el que compendia, con un estilo cuidado y muy personal, los episodios más sobresalientes de la vida de este fraile agustino llamado a convertirse en santo; modelo, por tanto, de virtud. Sin embargo, lo que más parece llamar la atención a Quevedo de la vida de Villanueva es la crítica social que realiza en sus sermones «con los que coincide ideológicamente» ${ }^{14}$, pues entre las anécdotas que convierten al hombre

9. Quevedo, Epítome, p. 119: «Habiéndose ofrecido tratar con don Francisco de Quevedo Villegas, de la información que está a mi cargo para colocar y beatificar al Venerable padre Fr. Alonso de Orozco, supe escribía la vida del bienaventurado fray Tomás de Villanueva, obra grande, y que no puede salir a la luz con la brevedad que yo deseaba, y viendo se llegaba el día de la Fiesta de su Beatificación, le pedí hiciese un Epítome para informar con brevedad la noticia de todos: acabose en doce días. Y por ser obra, que en pocas palabras da noticia de muchas obras: escrita con celo, devoción, y cuidado, me encargué de sacarla a luz, pareciéndome que en breve volumen se leerían muchas cosas bien hechas, poco menos bien dichas. El Autor quiere, que el poco tiempo en que se escribió le sirva de disculpa. Y yo deseo, que para los que lo supieren leer sea alabanza. Y que con esta prenda aseguren las esperanzas de la historia, en que ha diez años que trabaja». (Todas las citas del Epítome incluidas en este artículo hacen referencia a la edición de Carmen Peraita, Gobernar la república interior).

10. Quevedo, Epítome, p. 116: “dejando a todos con deseo de ver las Historia que promete, para servicio del Santo, y honra de nuestra nación, y lengua».

11. Quevedo, Epítome, p. 118: «Esperamos con afecto el cuerpo grande de la historia, donde se verá, que como ese Santísimo varón, digno de honrar el lado a los Ambrosios, y Paulinos, fue idea de Prelados, así su historiador es ejemplar del acierto en escribir semejantes materias: trabajo tan malogrado como intentado de muchos».

12. Quevedo, Epítome, p. 178: «Esta abreviada suma he sacado de mi historia que estoy escribiendo, de la que a cumplimiento de su voto escribió con tanta piedad y diligencia, y celo, el docto y reverendo padre Salón, de la orden de san Agustín, para que la noticia entretenga, informada con brevedad, hasta que en mayor volumen vea el mundo lo más que se ha podido recoger hasta ahora». Estas palabras no aparecen en la edición incluida en Todas las obras en prosa de D. Francisco de Quevedo Villegas, caballero del orden de Santiago (satíricas, políticas, devotas), Madrid, Diego Díaz de la Carrera, 1650, fol. 432.

13. Sobre esta cuestión, véase Jauralde, 1980 y 1998, pp. 412-414; Fernández Mosquera, 2004, p. 24; y Peraita, 2012, pp. 44-49.

14. Fernández Mosquera, 2004, p. 24. 
en santo aprovecha para reprobar algunos vicios públicos. En este sentido, como subraya Pablo Jauralde,

El librito transparenta algunas de las obsesiones de Quevedo durante aquellos años: su preocupación por la dejadez de funciones de los monarcas, con juicios asombrosamente explícitos [...] Esto, en 1620, cuando por su debilidad el Monarca se había convertido en una auténtica marioneta de las camarillas del poder. Los juicios sobre la corrupción del alto clero no son menos duros, y se justifican en el apasionado elogio a la pobreza del patriarca valenciano ${ }^{15}$.

El propio Quevedo dice en la dedicatoria al lector que «no puede carecer de precio referir hechos gloriosos de los santos varones, donde se alimenta el espíritu en cosas importantes a la república interior » ${ }^{16}$. Un concepto este último sobre el que Carmen Peraita ${ }^{17}$ articula su edición y estudio del Epítome, al defender que Quevedo ve a Tomás de Villanueva como ejemplo de gobernante espiritual que compendia sabiduría, virtud y autoconocimiento; prioridades que deberían presuponerse en un buen dirigente en lugar de la codicia, el nepotismo y, en definitiva, la corrupción.

Estos son algunos de los aspectos de la vida de Tomás de Villanueva que subraya Quevedo, quien construye su Epítome a partir de los datos aportados por Salón en su libro De los ejemplos, su principal fuente. Las huellas son evidentes pues realiza un ejercicio de reescritura con muchas supresiones, inevitables al tratarse de un compendio, pero realizadas con un objetivo determinado pues se refieren fundamentalmente a la parte doctrinal y erudita, la que menos sirve a su propósito. Peraita concreta esas estrategias de reescritura en la inserción de una censura implícita a los cortesanos en algunos pasajes, en la acentuación de rasgos humanistas y de rasgos neo-estoicos, en la incorporación de episodios que no aparecen en las fuentes, así como en la reelaboración de la trayectoria familiar ${ }^{18}$.

\section{IMITAR AL QUE IMITA}

Cuando en 1635 vio la luz el Sagrario de Valencia, el Epítome, primer texto impreso de Quevedo, debía de ser conocido y más en la ciudad del Turia, donde Tomás de Villanueva pasó parte de su vida y en donde siete años después de aquella primera edición madrileña de 1620 se volvió a imprimir ${ }^{19}$. No hay duda de que Castillo Solórzano conocía

15. Jauralde, 1998, p. 414.

16. Quevedo, Epitome, p. 125.

17. Peraita, 2012, p. 11.

18. Peraita, 2012, pp. 58-90.

19. EPITOME / A LA HISTORIA / DE LA VIDA EXEMPLAR, / y gloriosa muerte del bienauentura-/do Fr. Tomas de Villanueua, Re-/ligioso de la Orden de S. Au-/gustin, y Arçobispo / de Valencia. / aL ReY nuestro señor. / Autor do[n] Fra[n]cisco de Queuedo Villegas, / Cauallero 
bien este texto; es más, parece que redactó este apartado de su Sagrario de Valencia sin levantar la vista del Epítome salvo para trasladar, con muy leve maquillaje, aquello que contaba Quevedo. Lo que resulta complicado es saber qué edición pudo manejar, pues, desechando criterios geográficos -no del todo sólidos-, el cotejo de estos textos no arroja datos definitivos al presentar escasas variantes y poco significativas. Lo que está claro es que Castillo sigue, sin lugar a dudas, a Quevedo, y lo hace desde el comienzo (copiado literalmente), e incluso en la selección y en el orden de los acontecimientos de la vida del beato.

$\mathrm{Al}$ ser el texto de Castillo una breve vida inserta en un compendio, es de esperar que no aparezca dividido en capítulos. No obstante, quedan vestigios de aquellos cinco apartados del Epitome, pues mantiene su estructura y reproduce los comienzos de manera muy similar, con la excepción del que correspondería con el capítulo v. Quevedo lo inicia con una disertación sobre la muerte, la alusión a la asistencia masiva de los pobres a la sepultura y la solicitud de la beatificación, lo que en el texto de Castillo se reduce tan solo a este último aspecto. Por ello y por su extensión, no lo incluyo en el siguiente cuadro que permite apreciar los paralelos:

\section{Quevedo \\ Epítome}

Cap. I: Nació el bienaventurado don Tomás de Villanueva en la villa de Fuenllana en el campo de Montiel el año de $1487^{20}$.

Cap. II. Pasó el año del noviciado, con tal ejemplo en todas virtudes, con tanta humildad y obediencia, que siendo novicio era maestro de profesos $^{22}$.

\section{Castillo Solórzano Sagrario de Valencia}

Nació el bienaventurado padre don Tomás de Villanueva en la villa de Fuenllana, que es en el campo de Montiel, en la Mancha, el año de $1487^{21}$.

Pasó el año del noviciado con tanta perfección en todas virtudes, con tanta humildad y obediencia, que siendo novicio podía ser maestro de muchos ${ }^{23}$.

del habito de Santiago / [adorno] / EN valencia, / Con licencia, por Iuan Bautista Marçal, / junto a San Martin. 1627. / A costa de Lorenço Duran mercader de Libros, en / la plaça del Colegio del Patriarca. $8^{\circ}, 56$ fols. Sig.: A-G8. Real Biblioteca de Madrid DIG/vi/2288.E. Me consta la existencia de una edición realizada en Milán, Felipe Ghisulfo (Filippo Ghisolfi), a costa de Altobel Pisan (s.a.). Hay un ejemplar en la Biblioteca Nazionale Braidense de Milán que no he podido consultar, y que, según se indica en la ficha, fue «Pubblicato presumibilmente fra il 1656 e il 1660, periodo in cui fu governatore del Ducato di Milano Alonso Perez de Vivero, conte di Fuensaldana dedicatario dell'opera». La imprenta y librería de Ghisolfi en Milán estuvo activa entre 1631 y 1668. Después de esa fecha y en lo que quedaba del siglo XviI, no se divulgaría de manera exenta, sino en las distintas colecciones de las obras en prosa de Quevedo publicadas a partir de 1650.

20. Quevedo, Epítome, p. 127.

21. Castillo, Sagrario, fol. 29r.

22. Quevedo, Epitome, p. 137.

23. Castillo, Sagrario, fol. 31r. 


\section{Quevedo \\ Epítome}

Cap. III. Fue amante tan amartelado de la observancia y retiramiento de su religión y su celda, que desdeñaba, no sólo con desprecio sino con asco, las dignidades y cargos $^{24}$. Estando la majestad cesárea en Toledo en las casas del conde Melito, vacó el arzobispado de Granada ${ }^{25}$.

Cap. Iv. Repartió la renta del arzobispado, de suerte que a él no se le quedase otra cosa que el mérito de repartirla a los mendigos ${ }^{27}$.

\section{Castillo Solórzano \\ Sagrario de Valencia}

Asistiendo en Toledo el emperador Carlos Quinto, vacó el arzobispado de Granada ${ }^{26}$.

Las rentas de su arzobispado las repartía de tal manera que él no tuviese en ella más que tan solamente la gloria de haberlas repartido con los pobres $^{28}$.

Castillo Solórzano pisa sobre las huellas de Quevedo incluso en episodios que este incorpora frente a sus fuentes declaradas, en especial Salón. Carmen Peraita, quien ha estudiado y cotejado con minuciosidad los textos de estos dos últimos, señala a este respecto que:

En alguna ocasión, el Epítome presenta una versión diferente de un acontecimiento, por ejemplo el episodio de las tres lecciones que dicta Villanueva en la Universidad de Salamanca, y su despedida del mundo con el salmo In exitu Israel cuando ingresa en el convento, no aparecen en Salón ${ }^{29}$.

Lo particular es que el autor del Sagrario de Valencia también recoge estas anécdotas y de forma muy similar a como lo hace Quevedo. De manera que, por más que confiese estar siguiendo a Salón, no puede hacerlo al menos en algo que este ni siquiera cuenta:

Llegó en estas cosas la voz de sus grandes partes a Salamanca, y fue solicitado con codicia de aquella Universidad donde le ofrecieron por claustro la cátedra de moral. Por mostrarse reconocido a la demostración de aquella universidad, fue a Salamanca y leyó tres lecciones, y en la postrera donde fue oyente el rector, leyó aquel misterioso salmo In exitu Israel de Aegypto ${ }^{30}$.

24. Obsérvese cómo Castillo Solórzano prescinde de este tipo de valoraciones que para Quevedo son sustanciales.

25. Quevedo, Epitome, p. 148.

26. Castillo, Sagrario, fol. 33v.

27. Quevedo, Epitome, p. 161.

28. Castillo, Sagrario, fol. 38r.

29. Peraita, 2000 , p. 255 . Salón también dice que predicara este salmo, pero no en la Universidad de Salamanca, sino en la catedral y en las calles de esta ciudad, y además en 1521 y no en 1516 como Quevedo y Castillo señalan.

30. Quevedo, Epítome, p. 136. 
Tuvo noticia la ilustre academia salmantina. Y deseando tener allí tan grave sujeto, le ofrecieron por claustro la cátedra de moral. Estimó este favor y, reconocido del ofrecimiento, no quiso dejar de aceptar y así partió a Salamanca, donde leyó tres lecciones, y de la última fue su oyente el rector. Leyó aquel misterioso salmo “In exitu Israel de Aegypto»³1.

Situación semejante es la que se da con la alusión a esa criada que le hace ver a la madre de Tomás que este está usando un cilicio; personaje del que nada dice Salón ${ }^{32}$ :

Fue también en aquella tierna edad muy penitente, ayunando muchos días sin los que manda la iglesia, y disciplinándose con grande secreto. Halló un día su madre, donde él dormía, sus disciplinas, y fue grande el pesar y sentimiento que de ello tuvo ${ }^{33}$.

En esta edad donde la inocencia tiene abrigada la virtud, y fortalecida contra los halagos del mundo, se enamoró de la penitencia, de suerte que se cerraba a tener oración y disciplina, acompañando su terneza con silicio, lo que vino a noticia de su santa madre, por advertencia de una criada que aliñando el aposento donde tenía su cama, halló escondida la disciplina con testimonios de que la ejercitaba por devoción, lo que bastara a ser penitencia de sus culpas ${ }^{34}$.

En este tiempo, en tan breve edad, comenzó a darse a la penitencia, orando y tomando disciplinas en sus retiros, y contra su terneza usando traer silicio cosa que por advertimiento de una criada de su casa vino a saberlo su madre, que aliñando su aposento halló la disciplina escondida con muestras de que la tomaba más rigurosa que sus culpas en tan tiernos años pedían ${ }^{35}$.

Al margen de incorporaciones, Castillo Solórzano mantiene cambios realizados por Quevedo aun en pequeños detalles que solo se advierten conociendo ambos modelos: el que confiesa seguir y el que silencia. Tanto Salón como Quevedo inciden en la austeridad de Tomás de Villanueva, pero mientras el primero señala «que para mí basta un jubón cuando mucho de diez a doce reales» ${ }^{36}$, Quevedo dice modificando el precio: «Quiso comprar un jubón, pidióle el oficial tres ducados por él»s7, cantidad que conserva Castillo, «Concertando con un oficial un jubón, le pidió tres ducados por él» ${ }^{38}$. Una muestra más de que este es su modelo y no Salón.

Resulta más evidente todavía que está siguiendo a Quevedo en aquellos episodios que este toma del autor de De los ejemplos, pero que reescribe con su particular estilo. Baste citar el episodio sobre los juegos de la niñez con el que Salón subraya el temprano camino hacia la

31. Castillo Solórzano, Sagrario de Valencia.

32. Ni siquiera recoge este episodio en De los ejemplos.

33. Salón, Vida, p. 11.

34. Quevedo, Epitome, pp. 132-133.

35. Castillo Solórzano, Sagrario, fol. 30.

36. Salón, De los ejemplos, p. 176.

37. Quevedo, Epítome, p. 156.

38. Castillo Solórzano, Sagrario, fol. 36r. 
santidad: «Hízole también su madre [...] muy aficionado a la iglesia, y así, en poder andar, no había sacarle della. Allí era todo su paseo, y juegos de niño $[\ldots]$ tenía este devotísimo niño, por grande favor y por sumo contento, servir a las misas, limpiar los altares, ayudar a barrer la iglesia y hacer todos los oficios que en aquella tierna edad le permitían sus fuerzas en servicio de la casa de Dios ${ }^{39}$. Son datos que mantiene Quevedo, aunque otorgando una mayor intensidad e incluso emoción al ritmo enumerativo de los hechos narrados: «Tenía por dijes de niño y por juguetes la imitación de los oficios divinos, haciendo altares, ordenando procesiones, haciendo púlpitos de las sillas, predicando con las costumbres la doctrina que aun no cabía en su lenguaje» »0. Y lo hace con una retórica que debió de resultar atractiva a Castillo Solórzano ya que la reproduce con leves modificaciones que afectan, sobre todo, a las formas verbales: «A lo que más se inclinaba era a formar altares, a ordenar procesiones, hacer púlpitos de sillas, predicando en ellas» ${ }^{41}$.

Por tanto, resulta evidente que el Epítome palpita en este apartado del Sagrario de Valencia; unas veces, como copia directa y otras, como reescritura levemente disimulada con el propósito de desnudar el texto de los rasgos más característicos de Quevedo, de su particular léxico, de las continuas preguntas retóricas que amplifican o de los epifonemas con los que cierra los capítulos. Aquello que tiene que ver con el sesgo que Quevedo otorga a su obra lo elide, como si fuese consciente de no querer dejar rastro. Castillo es cauto porque prescinde de aquellos pasajes en los que Quevedo aprovecha para criticar la ambición de los gobernantes. De ese «el mal año no le hace tanto la falta del agua, como la falta de caridad en los ricos y en los prelados, que de hambre de los pobres hacen el precio de sus cosechas ${ }^{42}$ no queda nada en el Sagrario de Valencia. Y aun cuando la huella se pueda seguir, queda dulcificada. Sucede así en el episodio en el que Carlos V acude a escuchar el sermón del fraile. El rey llega antes de tiempo y le pide que baje a recibirle, a lo que el agustino responde que está estudiando y que si baja no podrá predicar y si ha de predicar no podrá bajar. Quevedo refuerza esta anécdota cargando contra la actitud de los cortesanos. En este sentido, recuerda Peraita que el episodio «conecta, por añadidura, con una recurrente preocupación quevediana: la relación del valido y el monarca» ${ }^{43}$. Quevedo insiste en que el emperador aparece acompañado de los grandes desde el principio, y mientras aquel comprende las palabras del fraile, estos se escandalizan; no son capaces de entender el sentido de tan sabia respuesta. Castillo Solórzano sigue indudablemente a Quevedo; también como él incorpora a los grandes desde el

39. Salón, De los ejemplos, pp. 15-16. En la Vida, aunque recoge el episodio, prescinde de estos detalles.

40. Quevedo, Epítome, pp. 131-132.

41. Castillo Solórzano, Sagrario, fol. 30.

42. Quevedo, Epítome, pp. 128-129.

43. Peraita, 2012, p. 66. 
inicio del episodio y señala que acuden a su casa y no a la iglesia, como dice Salón, pero, a diferencia de aquel, suaviza el tono y pondera mucho sus palabras. Su intención no es la misma, por eso evita su arrojo. De ahí que en lo que respecta a la actitud de los cortesanos, lo que para Quevedo es «despego y descortesía»" una reacción “algo resuelta» ${ }^{45}$.

Sirvan como última muestra del proceso de reescritura de Castillo Solórzano las supresiones de las referencias a la supuesta obra perdida de Quevedo ${ }^{46}$, que solo en una ocasión mantiene modificando el referente de una manera muy hábil. Quevedo cuenta que «Entró en la religión el año de 1516 en 24 de noviembre, y profesó año de 1517, en 25 de noviembre, día de santa Caterina mártir, como consta de su profesión, que va en la historia $)^{47}$, y Castillo reescribe «como se ve en su historia ${ }^{48}$, remitiendo a la hagiografía de la santa, con lo que el asunto queda resuelto.

La única novedad que aporta Castillo Solórzano en su remozado epítome es un poema en estancias ( $84 \mathrm{vv}$.) con el título de «Al beato don Tomás de Villanueva, arzobispo de Valencia. Canción». Con él concede a este "sagrario» un sentido común más allá de lo valenciano, pues incorpora una composición poética como cierre de cada una de las vidas de santos que lo componen.

\section{Castillo Solórzano, «Satélite de Quevedo»}

Al final de su hagiografía sobre Tomás de Villanueva, Castillo sigue insistiendo en que ha seguido en todo momento el libro de Salón. Oculta la utilización directa que hace del texto que Quevedo publicó 15 años antes sin que conozcamos la razón de tal silencio.

Sabemos que admiraba al autor de El Buscón. No es difícil encontrar reminiscencias en varios de sus textos. Resulta especialmente evidente en los poemas jocosos de los Donaires del Parnaso ${ }^{49}$, muchos de los cuales fueron leídos en la academia de Medrano, en la que coincidió con el maestro de la sátira ${ }^{50}$. Pero allí lo que encontramos son préstamos de neologismos, dilogías, tópicos o juegos verbales, además de imitación de

44. Quevedo, Epítome, p. 144.

45. Castillo, Sagrario, fol. 32v.

46. Quevedo, Epitome, p. 165: “Cosa admirable y de efecto milagroso y por ser sin número las cosas que milagrosamente obró en el socorro de los pobres y no llegar a historia el epítome, solo referiré lo que le pasó con un jubetero» y Quevedo, Epítome, p. 146: «lo que ellos conocieron en los sucesos y confesaron por las cartas que se verán en la historia el año de 1541».

47. Quevedo, Epítome, pp. 136-137.

48. Castillo, Sagrario, fol. 31r.

49. López Gutiérrez alude continuamente a esa influencia es su tesis doctoral, 2003 y Bonilla Cerezo (2008) analiza las huellas de Quevedo en varias de sus composiciones poéticas, centrándose en la sátira hacia los médicos.

50. King, 1963, p. 51. 
estilemas. Allí no hay copia extensa y directa de pasajes enteros. Utiliza los recursos que considera ingeniosos y acertados para inscribirse en una tradición que quiere encabezar, aunque, como señala Rodríguez Mansilla «parece darse cuenta de que no puede competir con Quevedo en la poesía satírico-burlesca, a riesgo de ser un eterno rezagado, siempre a su sombra $\aleph^{51}$. Quizá por eso intenta encontrar su camino y alzarse con un satisfactorio protagonismo dentro de los límites de la prosa, en donde tampoco es capaz de renunciar a la impronta de Quevedo. Lo que ocurre es que en el proceso de imitación el género influye. En la narrativa, la menor sonoridad hace menos evidente el plagio, y si solo es parcial, puede quedar diluido entre el magma de un texto más amplio que, además, carece del marchamo del ritmo y de la rima. En el Sagrario de Valencia, no hablamos de recreación de lo leído, del recuerdo de un fragmento que ha impactado o de una idea atractiva que emerge, sin control, en el proceso de creación. Estamos ante una copia consciente de todo un libro, pasada, eso sí, por el crisol de la reescritura; un mecanismo que Castillo Solórzano conocía perfectamente pues lo había practicado tiempo antes con una de sus obras, los Escarmientos de amor moralizados. Tras publicarla en Sevilla en 1628, vuelve a sacarla a la luz al año siguiente en otra ciudad y en otra imprenta con el título de Lisardo enamorado (Valencia, Juan Crisóstomo, 1629). También allí silencia que se trata del mismo texto sin los escolios morales y con una serie de cambios estilísticos y sintácticos que la remozan y que Giulia Giorgi ha estudiado de acuerdo a cuatro tipos de intervención que podrían aplicarse, aunque sea parcialmente, al caso del Sagrario de Valencia: interpolación de adjetivos; sustituciones de vocablos o de expresiones en pro de una mayor precisión léxica o como simple variatio; reelaboración de períodos enteros y revisión de la sintaxis a manera de expolitio; y redundancias y guiños al estilo culto ${ }^{52}$.

No hay duda, por tanto, de que Castillo Solórzano admiraba a Quevedo. Su estilo también está presente en la confección de El culto graduado, novela corta inserta en su colección Tardes entretenidas (1625). Y al margen de obras concretas, le siguió en esa corriente anticultista que explota en buena parte de su producción, especialmente a través de sus composiciones poéticas, cuya importancia reivindica Cossío al decir que

No han sido consideradas de modo alguno, y ciertamente debieron haberlo sido por su ingenio y por lo que representan en el cuadro de la poesía jocosa como satélite de Quevedo, al que manifiestamente imita muchas veces. Por Castillo Solórzano, y por otros ingenios semejantes, no es Quevedo una cumbre aislada en el paisaje literario de España, sino la culminación de una manera cultivada con menos fortuna por otros escritores y poetas ${ }^{53}$.

51. Rodríguez Mansilla, 2012, p. 20.

52. Giorgi, 2014, pp. 262-264; Giorgi, 2016, pp. 253-254.

53. Cossío, 1998, p. 268. 
Sin embargo, no fue Castillo Solórzano el único satélite de Quevedo ni en la poesía ni en lo que al Epítome se refiere ${ }^{54}$. Antes que él, el agustino fray Jerónimo Cantón escribió la Vida y milagros del B.P. y señor don Tomás de Villanueva (Barcelona, Sebastián y Jaime Matevad, 1623). Una obra en verso dividida en doce libros en los que alterna apartados sobre la vida del fraile agustino recién convertido en beato con reflexiones sobre aspectos generales vinculados a esta. Su fuente, como él mismo reconoce en las palabras que dirige al lector en los preliminares, no es otra que el Epítome:

hallé (y no acaso sino por orden del cielo), un libro no pequeño de cuerpo pero grandioso en el alma, compuesto por un gran caballero cuyo nombre es don Francisco de Quevedo Villegas, el cual sin conocelle llamo con todas veras grande, porque obras grandes legítimamente dan gran nombre a su autor.

Si bien es cierto, es más un modelo del que extrae la información del beato, que una imitación tan cercana como la que realiza Castillo Solórzano.

Tras la canonización de Tomás de Villanueva en noviembre de 1658, Juan de Cueto y Mena, dramaturgo, oriundo de Villanueva de los Infantes y afincado en Cartagena de Indias, escribió una Paráfrasis panegírica en forma de coloquio de la milagrosa vida y muerte del ilustrísimo señor santo Tomás de Villanueva, con la idea de que se representara en las festividades que dicha ciudad colombiana había organizado en 1660 para conmemorar la canonización. La obra, compuesta de 854 versos, está planteada como un coloquio entre personajes alegóricos (el Tiempo y las localidades de Villanueva, Alcalá de Henares, Salamanca y Valencia), que tratan de la vida del santo a partir de los datos que aparecen en el Epítome $e^{55}$.

También la obra de Quevedo parece estar en la base de la Comedia famosa de santo Tomás de Villanueva (1666), escrita por Juan Bautista Diamante. Y lo mismo se dice de una pieza teatral de Jacinto Alonso de Maluenda, hoy desaparecida ${ }^{56}$. Con todo, cualquiera de estas obras, ya sean consideradas recreaciones, adaptaciones o imitaciones, quedan muy lejos de la reescritura realizada por Castillo Solórzano.

\section{ÚLTIMAS REFLEXIONES}

En definitiva, la imitación de Quevedo en el Sagrario de Valencia es clara, pero ¿́por qué silenciarla cuando el apego a las fuentes se consideraba reconocimiento a la autoridad y respeto a la vida del santo? ¿Acaso

54. Peraita 2000, p. 251, n.1; 2004, pp. 267-268; y 2012, pp. 35-37.

55. Woodford, introducción a la edición de las obras de Cueto y Mena, 1952, p. 21.

56. Peraita, 2004, pp. 267-268; 2012, pp. 35-37. 
Castillo Solórzano se vio obligado a escribir su texto de una manera rápida para cumplir cuanto antes con la deuda que sentía hacia la ciudad o para tener una nueva obra en el mercado? ¿Se dejó llevar por el pragmatismo y siguió un texto que compendiaba de manera acertada y con un estilo atractivo la historia de Tomás de Villanueva? Desde luego era más fácil partir de Quevedo, que ya había hecho el trabajo duro de resumir a Salón. De hecho, Castillo lleva a cabo un epítome de un epítome, pues Quevedo compendia en 48 folios los poco más de 200 (411 pp.) del primer libro de Salón, impreso en $4^{\circ}$, y él resume o más bien reduce aquel en tan solo 15 folios de un texto en $8^{\circ}$.

Podemos pensar que se aferró al nombre de Salón como fuente, sin nombrar ni en una breve alusión a Quevedo, porque pensó que este no era un hombre de Iglesia, sino un escritor; un hombre de corte, polémico y polemista en los ámbitos intelectuales de la época en la que se publica el Sagrario de Valencia; por más que el Epítome se publicara a instancias y con el beneplácito de la orden de san Agustín. De hecho, por aquellos años Quevedo se había granjeado la enemistad de muchos y era blanco de las invectivas de varios como se muestra en el famoso Tribunal de la justa venganza publicado precisamente en Valencia en 1635. De manera que todo apunta a que quiso mantenerse dentro de cierta ortodoxia en un ámbito como el hagiográfico, en el que se adentraba por primera vez y del que probablemente esperaría algún rédito social, además de profesional, pues la obra está dedicada a toda una ciudad a la que alaba en términos que poco tienen que ver con lo religioso. Sin duda Castillo Solórzano era un consumado lector y un prolífico escritor, pero, en ocasiones como esta, conjugó lectura y afán por publicar de una manera tan interesante como peligrosa.

\section{Bibliografía}

Bonilla Cerezo, Rafael, «Pesadilla de médicos, veneno de enfermos: la sátira científica en Alonso de Castillo Solórzano», Edad de Oro, xxvII, 2008, pp. 47-104.

Castillo Martínez, Cristina, «La escritura hagiográfica de Castillo Solórzano: el Sagrario de Valencia (1635)», Edad de Oro, xxxvi, 2017, pp. 59-73.

Castillo Solórzano, Alonso de, Sagrario de Valencia, Valencia, Vicente Esparsa, 1635.

Cossío, José María, “Corriente quevedesca: Castillo Solórzano», Fábulas mitológicas en España, Madrid, Istmo, 1998, vol. 2, pp. 268-278.

Cantón, Jerónimo, Vida y milagros del B.P. y señor don Tomás de Villanueva, Barcelona, Sebastián y Jaime Matevad, 1623.

Cueto y Mena, Juan de, Paráfrasis panegírica en forma de coloquio de la milagrosa vida y muerte del ilustrísimo señor santo Tomás de Villanueva, en Obras de Juan de Cueto y Mena, ed. Archer Woodford, Bogotá, Instituto Caro y Cuervo, 1952.

Diamante, Juan Bautista, Comedia famosa de santo Tomás de Villanueva, en Parte veinte y tres de comedias nuevas, escritas por los mejores ingenios de España..., Madrid, Joseph Fernández de Buendía, 1665, pp. 1-45. 
Fernández Mosquera, Santiago, «Quevedo y los santos», Criticón, 92, 2004, pp. 7-37.

Giorgi, Giulia, «Alonso de Castillo Solórzano reescritor de sí mismo: algunas notas sobre los Escarmientos de amor moralizados y el Lisardo enamoradom, Edad de Oro, xxxıII, 2014, pp. 257-266.

Giorgi, Giulia, «El Lisardo enamorado de Alonso de Castillo Solórzano: una novela, múltiples géneros», Nuevos enfoques sobre la novela corta barroca, coord. Mechthild Albert et al., Frankfurt am Main, Peter Lang, 2016, pp. 247-260.

Jauralde, Pablo, «Escribió Quevedo una biografía extensa de Santo Tomás de Villanueva?», Mayéutica, 6/16, 1980, pp. 71-77.

Jauralde, Pablo, Francisco de Quevedo (1580-1645), Madrid, Castalia, 1998.

King, Willard F., Prosa novelística y academias literarias en el siglo XVII, Madrid, Anejos del вRAe, 1963.

López Gutiérrez, Luciano, Donaires del Parnaso de Alonso de Castillo Solórzano: Edición, estudio y notas, Madrid, Universidad Complutense, 2003, tesis doctoral.

Peraita, Carmen, «Observaciones preliminares para anotar el Epitome a la historia de fray Tomás de Villanueva de Quevedom, La Perinola, 4, 2000, pp. 251-266.

Peraita, Carmen, «Reescrituras hagiográficas: Tomás de Villanueva, Miguel Salón y Quevedo» en Studies in Honor of James O. Crosby, ed. Lía Schwart, Newark, Juan de la Cuesta, 2004, pp. 267-279.

Peraita, Carmen, Gobernar la república interior, enseñar a ser súbdito. Hagiografía y sociedad cortesana en Quevedo. Epítome a la vida de fray Tomás de Villanueva de Francisco de Quevedo, Pamplona, Eunsa, 2012.

Quevedo, Francisco de, Epitome a la historia de la vida ejemplar y gloriosa muerte del bienaventurado de fray Tomás de Villanueva..., Madrid, Viuda de Cosme Delgado, 1620.

Quevedo, Francisco de, Epítome a la historia de la vida ejemplar y gloriosa muerte del bienaventurado de fray Tomás de Villanueva..., Valencia, Juan Bautista Marzal, 1627.

Quevedo, Francisco de, Epitome a la historia de la vida ejemplar y gloriosa muerte del bienaventurado de fray Tomás de Villanueva, en Obras de Don Francisco de Quevedo Villegas, ed. Aureliano Fernández Guerra, Madrid, вAE, 1859, vol. 2, pp. 55-69.

Rodríguez Mansilla, Fernando, La picaresca femenina de Alonso de Castillo Solórzano. Teresa de Manzanares y La garduña de Sevilla, Madrid, Iberoamericana / Vervuert, 2012.

Salón, Miguel Bartolomé, De los grandes y singularísimos ejemplos que dejó de sí en todo de santidad y virtud, particularmente en la piedad y misericordia con los pobres, el ilustrísimo y reverendísimo señor don Tomás de Villanueva, arzobispo de Valencia y religioso de la orden de san Agustín, Valencia, Pedro Patricio Mey, 1588.

Salón, Miguel Bartolomé, Libro de la santa vida y milagros del ilustrísimo y reverendísimo señor Don Fr. Tomás de Villanueva, arzobispo de Valencia, de la orden de san Agustín, beatificado por nuestro santísimo padre Paulo V. Año 1618, Valencia, Juan Crisóstomo Garriz, 1620.

Villegas Rodríguez, Miguel, Miguel Bartolomé Salón (1539-1621): insigne agustino valenciano, Madrid, Revista Agustiniana, 2001. 